\title{
Vorwort \& Dank zur 1. Auflage
}

Ohne Explosivstoffe wäre unsere heutige Welt nicht vorstellbar. In Munition dienen Sprengstoffe, Treibmittel und Pyrotechnika dem Schutz und der Verteidigung. Gleichwohl können Munition und Explosivstoffe in den falschen Händen aber auch Zerstörung und Chaos bedeuten.

Weniger kontrovers ist der Einsatz von Explosivstoffen in der Entwicklung unserer Lebensräume. Straßen, Tunnel sowie Bauvorhaben auf felsigem Grund sind ohne Explosivstoffe genauso undenkbar, wie Abbrucharbeiten an Bauwerken oder die Gewinnung von Rohstoffen über und unter Tage. Mit Explosivstoffen können Halbzeuge einfach und kostengünstig umgeformt und komplizierte Materialkombinationen gefügt werden. Fast schon vergessen ist der massenhafte Einsatz von Explosivstoffnieten im Flugzeugbau. Eine Fülle von Gasgeneratoren sorgt heute in nahezu jedem Kraftfahrzeug für Sicherheit bei Unfällen, wodurch schon unzählige Leben gerettet oder schwerere Verletzungen verhindert wurden. Leucht- und Rauchsignale helfen in Notsituationen. Feuerwerke krönen Fest- und Feiertage. Die Erkundung des Weltraums wäre ohne die vielfältigen energetischen Materialien in chemischen Antrieben, Aktuatoren, Trennschrauben und Schneidschnüren nicht möglich. Schließlich eröffnet der Einsatz von Explosivstoffen die Herstellung neuer Materialien (SHS bzw. Detonationssynthese) die auf andere Weise nicht zugänglich wären.

Ein deutschsprachiges Lexikon zum Thema Sprengstoffe, Treibmittel und Pyrotechnika, das auch Zugang zur Primärliteratur eröffnet, fehlte bislang und wird mit diesem Buch nun vorgelegt. Auf 460 Seiten finden sich 590 Einträge mit 133 Tabellen, 82 Abbildungen, über 200 Formeldarstellungen sowie knapp 900 Literaturstellen.

Die Auswahl der Einträge ist naturgemäß subjektiv und orientiert sich an meinen gegenwärtigen und früheren Arbeitsgebieten.

Ein Buch, zumal eines, das den Anspruch einer Enzyklopädie erhebt, kann und darf nicht das Werk eines Einzelnen sein. Ich bin daher vielen aktuellen und ehemaligen Kolleginnen und Kollegen zu großem Dank für Hinweise, Informationen und Kommentare verpflichtet.

Stellvertretend für viele danken möchte ich an dieser Stelle Herrn Diplomphysiker Roland Wild, stellvertretender Direktor i. R. der Außenstelle Heimerzheim des Wehrwissenschaftlichen Instituts für Werk-Explosiv- und Betriebstoffe (WIWEB) für die Begutachtung des Manuskripts, seine wertvollen Hinweise und die Bereitschaft, ein Geleitwort zu schreiben!

Ich wünsche Ihnen nun viel Freude beim Lesen und Nachschlagen und würde mich sehr freuen, auch Hinweise auf Fehler und notwendige Ergänzungen für zukünftige Auflagen dieses Buches zu erhalten.

Kaiserslautern im November 2017

Ernst-Christian Koch 
